of the ankle, and then amputation ceased to be the common practice. Sir Astley Cooper advised resection of the joint in almost all cases. Since his day surgical opinion has fluctuated, no definite course being laid dowı.

'There are to-day for consideration three methods of treatment: (1) IReduction; (2) partial or complete excision with reduction; (3) amputation, primary or secondary.

The coinparatively modern authorities in surgical litorature in America - Ashhurst, Hamilton, Gross and Agnew - advise strongly that, as a rule, amputation be done. The English authorities, on the other hand, - Holmes, Bryant, Holthouse and Erichson - are very conservative, advising an attempt to save the limb by excision, reserving the hadly comminuted cases for amputation. 'These views merely repeat what the profession has for a long time maintained. No very detinite rules of procedure has been laid down by any one. 'This may be impossible and impracticable; but it seews that to-day this may safely be done.

'Where are two things to bo considered in deciding what to do with any case of this injury : (1) The extent of the laceration of the soft parts ; (2) the amount of iujury to the bones.

(1) If the laceration is 80 great that the foot is useless, amputation is indicated; and amputation is indicated in only two other instances-old age and sepsis.

(2) If this laceration is not great, and the dislocation can be reduced, it should be reduced without excision, proper drainago being provided both anteriorly and posteriorly to the joint.

(3) If the laceration is not great and reduction is impossible, then an excision should be done, either partial or complete.

(4) If there is great injury to bone whether the dislocation can or cannot be reduced, a partial or complete excision should be done.

Aseptic surgery regards all fresh accident wounds, particularly those counected with the joints, as comparatively safe $80 \mathrm{fur}$ as immediate danger to life is concerued, aud if expectant treatment, as indicated above, is instituted in these cases, the chances for a useful foot and ankle-joint are very great. The best results from expectant methods of treatment of compound dislocations of this joint are due to aseptic methods in every instunce. All compound dislocations of the ankle-joint, however small the wound in the soft parts, should be thoroughly cleansed. In order to insure an aseptic wound, the small opening should be enlarged so that the joint may be thoroughly examined and cleansed in every part.

I have carefully examined the records of all cases of compound dislocation of the ankle reported in the medical literature since 1878. I found a total of thirtyeight cases, in which the end-result is known. 'Twentytwo were reduced without operation. In eight the astragalus was removed. In six a partial excision was done. In two a complete excision was done. The end-result in these cases were, as to usefulness of the foot, excellent. As to the mortality, one cuse died of sepsis, aged 64 , in 1883 ; one case in 1877 , came to amputation. The age of the oldest was sixty-four years; of the youngest, fifteen years. Only those cuses were taken for study in which the end-results were known.

'Through the kindness of Dr. H. H. A. Beach, uuder whose care the case came at the Massachusetts General Hospital, I am allowed to make the following report of a case of forward compound dislocation of the ankle-joint which under conservative and nonoperative treatment recovered with a useful though stiff ankle-joint.

E. D., age ten years.

A pril 24, 1888. Cunght foot between the tracks of a railroad turntable; was held fast and thrown violently to the ground. Shortly afterward an antiseptic dressing and side splints were applied to the foot. Ho was brought to the accident-room five hours after the injury. On examination, a compound dislocation of the right ankle backward, with fracture of the internal walleolus was found. There was an extensive laceration of skin across the dorsum of foot from one malleleolus to the other forming a gaping wound two inches wide, exposing the extensor tendous. The anterior tibial tendon was torn, and the dorsalis pedis artery ruptured. The tip of the internal malleolus was found broken and the bones of the leg displaced backward the heel being shortened and the upper articular surface of the astragalus lying anteriorly.

May 4th. A small abscess was opened at the tip of one malleolus.

July. Entirely healed. Extensive cicatrix across dorsum of foot. Complete ankylosis at ankle-joint.

August lst. Up and about on crutches.

March, 1891, two years and nine months after the wound healed, the boy uses the injured foot and leg as well as the other. The tiba are of the same lengtli. The right calf measures 10 inches. The left calf measures $11 \frac{1}{2}$ inches. He walks with a slight limp, which is not noticeable to many. There is a slight tendency to walk on the outer edige of the foot. After walking all day, particularly in damp weather, there is some pain and a little stiffuess about the foot.

In conclusion, extreme conservatism should characterize the treatment of recent compound dislocations of the ankle-joint. Such treatment as is emphasized above should, in the large majority of cases, result in a useful ankle-joint and foot.

\section{Ulinital g্Department.}

\section{TWO CASES OF COMPOUND FRAC'TURE ANI) DISLOCA'TION A'T THE ANKLE-JOIN'T:1}

BV A BNicir pos'r, a.1).

Visiting Surgeon, Boston City Hospital.

Thess: two cases were shown to the Society for Medical Improvement, to illustrate the fact that very serious compound dislocations may recover under modern wound treatment.

In the first case the accident occurred on August 20, 1890. The patient, who was a teamster, was thrown from his wagon on to the pavement. When brought to the hospital, there was a wound below the external malleolus of the left tibia. 'The astragalus was broken, and one-half of it protruded through this wound, and the foot was strongly inverted. Before any surgical procedure was begun, all the parts about the wound were carefully cleansed and washed with a solution of corrosive sublimate of a strength of 1 to 3,000 . The wound was then enlarged. It was absolutely impos. sible to replace the misplaced portion of the astragalus, and it was removed. 'The foot was restored to its normal position, and a dressing of gauze soaked in a 1

I Shown before the Boston Sooloty for Medical Improvement, Jaunary $25,1892$. 
to 2,000 solution of corrosive sublimate applied. plaster-of-Paris bandage was then applied over all, exactly as might be done for a simple fracture.

On the evening of the $21 \mathrm{st}$ the temperature was $100^{\circ}$; on the evening of the $22 \mathrm{~d} 101^{\circ}$; on the morning of the $23 d$ it fell to $99^{\circ}$. On the 25 th it was between $100^{\circ}$ and $101^{\circ}$; it then fell to $99^{\circ}$, where it remained for a few days, and for the remainder of the time was practically normal. 'The first dressing was done on September 2d, when the wound was healed, except a small granulating area about half an inch square. The circular plaster was replaced and retained until September $22 \mathrm{~d}$, when the wound was entirely healed and some motion in all directions was found.

'This patient was kept long in bed, as he had lost his left arm many years before and was unable to use crutches. He was thirty-two years old at the time of the accident, and was the driver of a beer-wagon. He had lost his arm some years previous from a compound fracture of the hand, which to his eyes was much more serious than the accident to his foot and his surprise and delight at retuining his leg was very great. He now walks without any support. When shown to the Society, he walked with both feet bare on the level floor with but a slight limp, but in going up or down stairs there is evident disability.

The second case was Mr. A. L. P., aged forty at the time of the accident, which occurred on April 23, 1888. When brought to the City Hospital on that date the articular end of the tibia projected more than two inches through a wound over the outer malleolus. The foot was turned inwards and upwards so that the exposed bone lay over the heel. 'The periosteum was stripped up from the tibia, and both malleoli broken off. 'The accident resulted from a fall of about six feet from a ladder that broke while he was upon it. He came down feet foremost on to an inclined plank driveway.

Everything was made clean; the incision was enlarged upwards; and fragments, of which there were many small ones, were removed with forceps, fingers and irrigation. As the removal of the fragments seemed incomplete, an incision was made over the inner malleolus, and the tingers passed freely through the joint. 'The bones were then replaced, the periosteum adjusted and secured in place with a stitch or two of cut-gut, the skin carefully replaced and stitched with silk. No drainage-tubes were used, but a stitch or two omitted to allow eusy exit for uny discharge. Irrigation with corrosive-sublimate solution was freely done during the operation, and corrosive gauze dressing was applied. 'The whole was carefully enveloped in a plaster-of-Paris bandage.

The first dressing was dono on May $7 \mathrm{th}$, when there was slight external sloughing at the site of the original wound. 'There was afterwards slight suppuration at that point, but it was confined to the exterval portions of the original wound.

'The patient was sent home on June 3d, and made a good recovery. When shown to the Society, there was motion at the joint in all directions, and the patient declared that the foot was as good as before the accident.

The principle point in the treatment of these cases - which were not unique, though extremely favorable examples of what may be done with compound dislocations at the present day - was the disinfection of the wound, but the immobility, as euforced by the plaster buuduge, was of almost equal importance.

\section{PEROXIDE OF HYDROGLN AS A DEODORIZER, IN CANCER OF 'THE U'TEIRUS.}

BY GLoRak W, KAAN, M.D.

Surgeon to Out-I'atients, Free Hospital for Women, Boston.

THe value of peroxide of hydrogen in washing out sinuses and abscess cavities, has led me to use it recently as a vaginul injection in cancer of the uterus; and with gratifying results.

My cases have been few; but in each the distinctivo cancerous odor was noticeable about the patient before the use of the peroxide of hydrogen, and absent afterwards. In one out-patient cuse the fetor was so pronounced, that the air of the room seemed saturated with it, the moment she entered. When I last saw her in making an examination no odor was perceptible a foot from the vulva, and only slightly so close to it. In this case she had used the injection the night before, and a cancerous mass as large as a man's fist, hangs in the vagina, within two inches of the vulva. This case had had palliative treatment in the hospital, by curetting, Paquelin's cautery, and chloride of zinc applications. When she first came to me the disease had extended over the whole anterior vaginal wall; since then the peroxide of hydrogen has been used, and the anterior wall is clear. It seems to me that the injections have had some curative action.

Further observation, of course, is necessary; but bearing in mind what Sir Spencer Wells says of cancer and cancerous disease, that everything in relation to it is so important that nothing should be thought a trifle, and my material being limited, I venture to state the facts as they appear to me in this case.

Regardless, however, of any value it may have as a curative agent, its use as a deodorizer, and this without substituting another odor for the cancerous one, makes it of inestimable worth in adding to the comfort of the patient, where palliative treatment alone is all that remains.

The method of using has been to take about an ounce of the peroxide of hydrogen and an equal quantity of water, warmed by being placed in a pan of hot water, and injected through a soft rubber catheter, so that the injection shall be sure to reach the back part of the vagina. Such an injection once or twice a day has been sufficient.

\section{Medital Bragregk.}

\section{RECEN'T PROGRESS IN PUBLIC HYGILNE.}

BY 8. W. ABHO'I"1, M.D.

(Conoluded from No. 13, pago 813.)

CHEMICAI AND BACTERIOLOGICAL INVESTIGATION OF ,THE SYSTEM OF SEWAGE TREATMENT AT I'O'SDAM.

I' $\mathrm{r}$ is pointed out in the introduction that the object to be attained in the purification of sewage-water is the destruction of all the infectious matter contained therein. It is also necessary to effect such changes that the liquid after treatment may no longer be liable to putrefaction. The success of any process in accomplishing these results must be tested by chemical and bucteriological analyses. The chemical investigations should in the main be relied upon for the de-

5 13. Proskauer and Dr. Nocht: Zoilschrift filr Hygiene, vol. x, 1891, 1. 111. 